\title{
Access of Ground Water Quality with Associated Physico-Chemical Parameters of Cuttack District, Odisha, India
}

\author{
Manas Ranjan Naik, Manas Barik, V.N. Jha, Sunil Kumar Sahoo, Naresh Kumar Sahoo
}

\begin{abstract}
The aim of present investigation was to analyze the variations in the physio-chemical properties of the ground water of Cuttack district Odisha. In the present study 98 samples were collected and analyzed to assess the quality of ground water. The $p H$, electrical conductivity (EC), total hardness and total alkalinity of the collected 98 samples were in the range of 4.6-7.3, $36-4550 \mu \mathrm{S} / \mathrm{cm}, 40-200 \mathrm{mgl}-1,20-680 \mathrm{mgl}-1$ respectively. Similarly, the other important water quality parameters such as; chloride, nitrate sulphate and phosphate concentration were varies between BDL-327, 1.8-86.25, BDL-194 and BDL to 3.2 mgl-1 respectively. The $p H$ of the alluvial groundwater is controlled by the HCO3. The fluoride concentration was varies from BDL to $2.38 \mathrm{mgl}-1$. Apart from few samples, $90.81 \%$ fluoride contaminated samples comes under the category of quality group A (< 1 mgl-1flouride). Similarly, out of total samples collected only in three samples the uranium concentration estimated to be more than 5ppb. Among the water quality parameters there exist a positive correlation between $\mathrm{pH}$ and fluoride with a correlation coefficient of 0.641. From the correlation analysis it is found that, higher concentration of fluorid correlated with higher pH. Similarly the correlation coefficient between calcium and chloride is very high i.e. 0.500 , which strongly supported the existence of calcium in the study area is predominantly in the form of $\mathrm{CaCl2}$. Most of the ground water samples meet the requirements of the WHO drinking water standards with respect to salinity, main constituents and potentially toxic trace elements such as uranium.
\end{abstract}

Keywords: Ground water, Fluoride, Uranium, Correlation, Physico chemical parameters.

\section{INTRODUCTION}

Groundwater is the major source of quality water for consumption of human throughout the world. However, widespread contamination of ground water has created more threats to its quality rather than depletion. In most cases, groundwater quality depends on quantity of precipitation, extent of recharge and quality of discharge water, rockwater interaction, dissolution, weathering of rocks. Further, the anthropogenic sources such as; rapid and unplanned urbanization, intensive agricultural and industrial activities causes serious threat to the ground water quality. The occurrences of fluoride in groundwater resources of India are regarded as a major concern in the study area. Quality of groundwater is closely involves with the human health, even traces of uranium seriously causes human health hazards.

Revised Manuscript Received on September 14, 2019.

Manas Ranjan Naik, Department of Chemistry, ITER, Siksha 'O' Anusandhan (Deemed to be University), Bhubaneswar, Odisha, India.

Manas Barik, Department of Chemistry, ITER, Siksha 'O' Anusandhan (Deemed to be University), Bhubaneswar, Odisha, India.

V.N. Jha, Bhabha Atomic Research Centre, Trombay, Mumbai, Maharashtra, India.

Sunil Kumar Sahoo, Bhabha Atomic Research Centre, Trombay, Mumbai, Maharashtra, India.

Naresh Kumar Sahoo, Department of Chemistry, ITER, Siksha 'O' Anusandhan (Deemed to be University), Bhubaneswar, Odisha, India.
Studies have reported toxicity of uranium in drinking water showing effects to various types of tissues and organ system like kidney [1] and in bone tissues [2]. According to the U.S. Environmental Protection Agency (USEPA) and World Health Organization (WHO) chemically, permissible limit of uranium is $30 \mathrm{ppb}$ [3], [4]. Once the uranium leaches to the water system, its solubility depends on many factors like $\mathrm{pH}$, temperature, oxidation reduction potential (ORP) [5] and total dissolved solids (TDS).

Therefore, in the recent decade continuous monitoring and evaluation of groundwater quality are very essential to characterize groundwater quality for sustainable groundwater resource management and to prevent further its contamination in the study area. Therefore, in the present investigation the quality of drinking water and its spatial distribution of associated physic-chemicals parameters of Cuttack district of Odisha, India has been explored.

\section{MATERIALS AND METHODS}

A. Study area description and water Sampling

The Cuttack district of Odisha is a part of the Mahanadi delta and extends from 840 o 58 ' to 86 o 20'east longitudes and from 2003' to 20o40' north latitudes. Cuttack district comprises a total area of is 3932 sq. $\mathrm{km}$. The district of Cuttack is comprises with three sub-divisions, i.e. Cuttack Sadar, Athagada and Banki. The population density is 595 person per sq.km of area.

A total of 98 samples were collected systematically as per the grid prepared $(6 \mathrm{X} 6 \mathrm{~km})$ from the Cuttack district of Odisha, during the post monsoon period between Novemeber to January. The sample were collected in polypropylene bottles soaked in $15 \%$ (v/v) HNO3 for one day followed by rinsed with double distilled water previously.

\section{B. In-situ parameters}

In situ parameters like ORP, temperature, $\mathrm{pH}$, TDS, electrical conductivity, and DO were measured in field using $\mathrm{HACH}$ (USA) portable multi-parameter water analysis kit (Make HACH CO, USA, Model Q40d Dual input Cat:8506000+ MTC10101). At every sampling location site, the geographic position was recorded by a hand-held Global Positioning System (GPS) (Make Gramin, and model Etrex 20). Similarly Gamma radiations of each sampling points were measured by radiation survey meter (MakePolymaster, Belarus, Ltd and model PM-1405.

Published By: Blue Eyes Intelligence Engineering \& Sciences Publication 


\section{Reagents and chemicals}

All the chemicals and reagents employed in the present study were either of analytical grade (AR) or laboratory grade (LR) and obtained from Hi-media (India), Sigma Aldrich USA, Merck (India) and Millipore India.

\section{Analytical Procedure}

$100 \mathrm{ml}$ collected water samples were acidified and filtered through 0.45 cellulose nitrate filter paper by a vacuum pump followed by measurement of Uranium was carried out in LED Fluorimeter after adding fluorescent enhancing agent Lumex Flourate (Make- Lumex Fluorate, Russia, Model Fluorimeter, Lumex Fluorate $-02 \quad-4 \mathrm{M}$ Analyzer). Another aliquot of $500 \mathrm{ml}$ of the collected samples were also filtered as described above without acidification and employed for analysis of other water quality parameters as per the BRNS recommended protocol. Alkalinity, hardness and chloride were measured by titration method as per the standard method of water and wastewater (APHA 2005) on the next day after sampling. For all preparation of standards and dilutions, double distilled water was used. Nitrate analysis was performed by Thermo (Make: Thermo Fsischer scientific USA Model: Orion 9796 BNOP Orion Nitrate sensing sure flow combination electrode and Orion Star A214 pH/ISE benchtop meter ) ion selective electrode methods. Sulphate concentrations of the collected samples were measured by gravimetric methods as per CPCB India. Fluoride was analyzed by Thermo (Make:Thermo Fsischer scientific USA Model: 9609BNWP - Orion ion plus sure flow combination Fluoride ion selective Electrode and Orion Star A214 pH/ISE benchtop meter USA) ion selective electrode methods. Measurement of phosphate was performed by stannous chloride method as per standard method of water and wastewater [6]. For all spectrophotometric determination, double beam UVVisible Spectrophotometer was used (Thermo Evolution 220 , USA Model).

\section{RESULTS AND DISCUSSION}

\section{A. Electrical conductivity (EC)}

The electrical conductivity (EC) of the collected groundwater post monsoon samples are in the range of 36$4550, \mu \mathrm{S} / \mathrm{cm}$ for the district of Cuttack. In the present study, the average electrical conductivity (EC) of the collected groundwater samples are varies between $660, \mu \mathrm{S} / \mathrm{cm}$ for post monsoon samples Cuttack. The maximum electrical conductivity in the present study is well supported by several literatures reported value in the ranges of 1590.01$5152 \mu \mathrm{mhos} / \mathrm{cm}$ [7], [8]. The maximum percentage $\%$ of collected samples i.e. $75.51 \%$ (74 Out of 98) have an electrical conductivity less than $750 \mu \mathrm{S} / \mathrm{cm}$ for post monsoon which are under acceptable category of " (B) good or "excellent" (A) for irrigation water source as per the Buero of Indian standards [9]. Few samples i.e. 05 numbers out of total collected samples of 98 post monsoon period were found to be out of the acceptable range as per BIS i.e. beyond $2250 \mu \mathrm{S} / \mathrm{cm}$ (group D). Therefore, these samples were unsuitable for consumption of human, owing to their elevated salinities. The maximum permissible limit of electrical conductivity in drinking water is 1400 $\mu \mathrm{mhos} / \mathrm{cm}$ [4],[8]. When the values of electrical conductivity exceed $3000 \mu$ mhos $\mathrm{cm}-1$, the germination of crops badly affected which reduces the crop yield.

Most of ground water samples with elevated electrical conductivity greater than $2250 \mu \mathrm{S} / \mathrm{cm}$ are situated near the river bank of Mahanadi containing alluvial soil, for instance: C17 Chasabarabati (EC $2840 \mu \mathrm{S} / \mathrm{cm}$ ), C-21 Atanda (EC $2650 \mu \mathrm{S} / \mathrm{cm}$ ), C-24Khairapanga (EC $2330 \mu \mathrm{S} / \mathrm{cm}$ ), C-37 Pathapur (EC $3260 \mu \mathrm{S} / \mathrm{cm}$ ), C-48 Patapur (EC 3050 $\mu \mathrm{S} / \mathrm{cm}$ ), C -86 Sansekharpur (EC $3170 \mu \mathrm{S} / \mathrm{cm}$ ) are falls near the river bank of Mahanadi. In addition, the chloride concentration in the above mentioned samples found to be high in the range of 173-286 mgl-1. The higher the concentration of electrolytes in water, the more is its electrical conductance. Similar decrease in conductivity profile of ground water in monsoon period is also reported in literature [10]. Generally, samples with high EC found to be in $\mathrm{NaCl}$-dominated waters. Whereas, In the conductivity of above $3000 \mu \mathrm{S} / \mathrm{cm}$, which believed to be consist of more than $60 \%$ chloride and sodium. Thus, the remaining majority of the samples $\mathrm{NaCl}$ may not be the prevailing constituent in the collected alluvial groundwater samples. In coastal regions, particularly Cuttack intrusions of sea water into river water probably an auxiliary source of salinity. Further, dilution of rock salt is a major source of salinity in alluvial groundwater in the study area. In addition, the higher salinity might be augmented by long-term irrigation.

\section{B. Dissolved oxygen}

The oxidation-reduction (redox) condition of groundwater is playing a vital role in regulating the aqueous speciation of trace elements, mainly uranium. Uranium is found to be soluble under oxic conditions. In general, the ideal dissolved oxygen concentration in drinking water should be $5.0 \mathrm{mgl}-1$. In the present study dissolved oxygen profile found to be well match with that of the ideal value of DO (min. 0.95 mgl-1, max. 6.17 mgl-1post monsoon). The median dissolved oxygen in the collected groundwater is $3.54 \mathrm{mgl}-$ 1 for post monsoon period. The median and maximum value clearly indicated that slightly reducing conditions existed in the sample collected area at a number of sites. Similar DO concentration was also reported by several authors in literature for instance; 4.32-6.83 mgl-1 [11], 4.18-7.4 mgl-1 [12].

Considering $0.5 \mathrm{mgl}-1$ of dissolved oxygen as an arbitrary value for the onset of reducing conditions, only one (1) out 98 collected samples for post monsoon period of the study area found to be exhibit reducing conditions,. Thus very less percentage of the collected samples can be classified as reduced and anoxic groundwater. This is quite obvious that anoxic groundwater is very uncommon in subtropical and arid regions than in temperate regions, which might be due to the higher rates of organic carbon mineralization at higher groundwater temperature and much slower and infrequent transport of TOC through the unsaturated zone. In addition, sewage and other waste might be responsible for the low value of DO [10]. 


\section{Fluoride profile}

The minimum and maximum fluoride concentration varies from BDL-2.38, mgl-1for the post-monsoon samples of Cuttack. In the present study the median concentration of fluoride is 0.37 in Cuttack district of Odisha during the post monsoon period (min. BDL mgl-1, max. $2.38 \mathrm{mgl}-1$ ). The maximum permissible limit of fluoride set by WHO (2011) is at $1.5 \mathrm{mgl}-1$ as well as Bureau of Indian Standards [9]. Concentration of fluoride in potable water is up to $1.0 \mathrm{mgl}-1$ does not cause dental growth, but beyond $1.5 \mathrm{mgl}-1$ cause health ailments [4]. Apart from few samples, maximum samples $90.81 \%$ (98 samples) post monsoon comes under the category of quality group A (< 1 mgl-1fluoride). Similarly, 8 are categorized under group B (between 1- 2 mgl-1) post monsoon. However one outlier contains a significantly higher fluoride concentration in the samples code C-11 (Pithakhai, Narassinghapur) is $2.38 \mathrm{mgl}-1$ which is harmful for consumption of human. The Frequency distribution of fluoride concentration of Cuttack districts for post monsoon samples are shown in Fig. 1 (a), (b). More than $90.81 \%$ collected water samples, the concentration of fluoride in the water is deficient than the WHO guide line, this is probably due to dilution by rain water, because the study area belong to a rain shadow area.
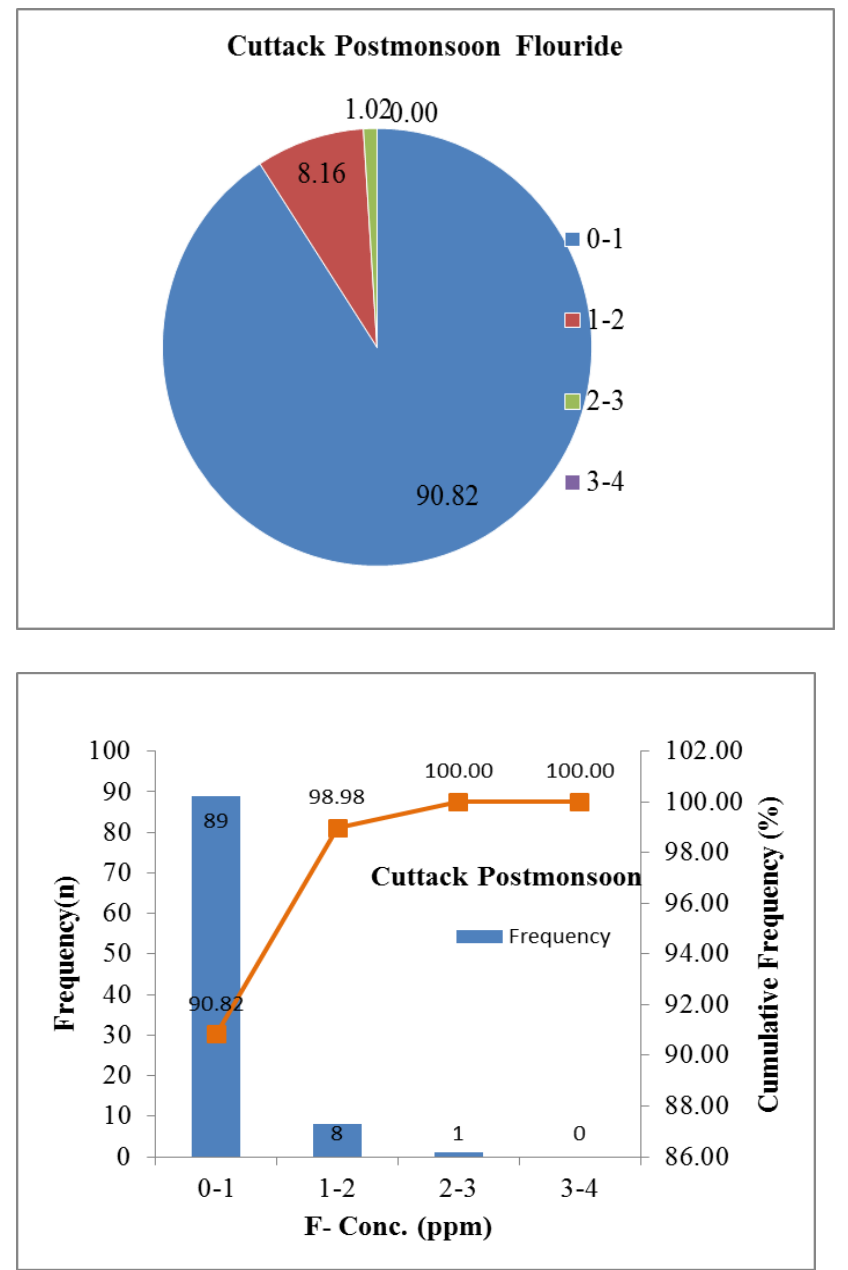

Fig. 1. (a), (b) Frequency distribution of fluoride concentration of Cuttack districts for pre monsoon samples.

There are several literature reports that the concentration of fluoride in drinking water found to be very high in 27 districts out of 30 in Odisha consequently, enhances acute health disorders [13], [14]. Similar concentrations of fluoride also have been reported by several literatures in the ranges of $0.17 \mathrm{mgl}-1$ to $5.602 \mathrm{mgl}-1$ [15]. The concentration of fluoride in Angul and Talcher zone varied 0.1 to $4.4 \mathrm{mgl}-$ 1 with an average value of $1.2 \mathrm{mgl}-1$ [11], [12] . During post monsoon period in some study area the concentration of fluoride is found deficient than the WHO guide line which might be due to dilution by rain water. Fig. 2 represented the spatial distribution of fluoride in post monsoon period of the Cuttack district of Odisha.

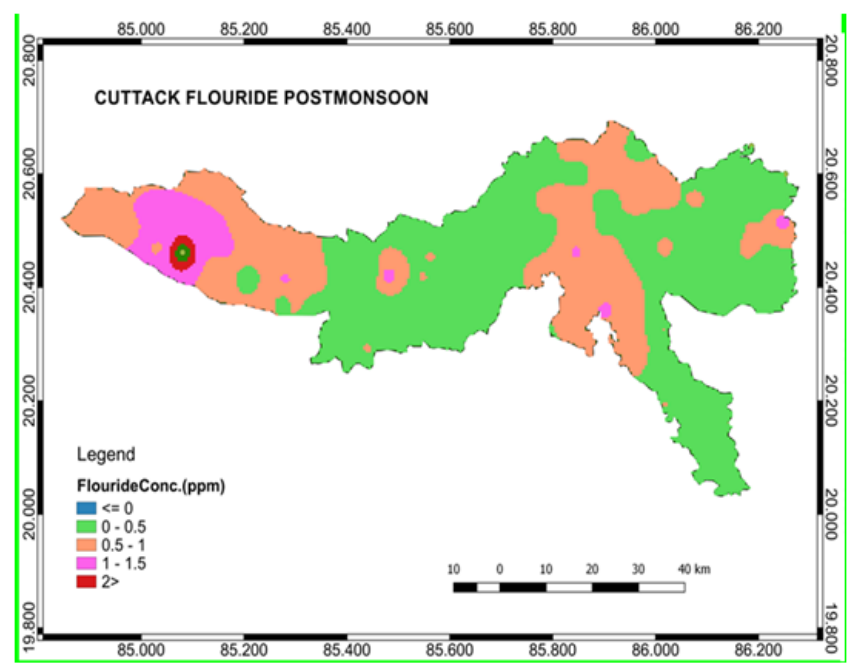

Fig. 2. Spatial distribution of fluoride in post monsoon period of Cuttack and Jajpur districts.

\section{Uranium Profile}

In nature uranium occurring in sediments, in the form of crystalline rocks and minerals such as granite, phosphate deposits, lignite as well as in uranium minerals such as uraninite, carnotite and pitchblende [16]. Mostly, groundwater is contaminated with uranium owing to the water and rock interactions as well as leaching processes. In the present study, the average concentration of dissolved uranium $(\mathrm{U})$ in groundwater samples is $0.65 \mathrm{ppb}$ for post monsoon period for the Cuttack district of Odisha. Similarly, the minimum uranium concentration found to be BDL and maximum of $6.5 \mathrm{ppb}$ for post monsoon period of the study area. Similarly uranium concentration in ground water of India reported in several literatures for instance; 1.08 to $35.83 \mathrm{ppb}$ in Kumaun and Siwalik [17], 1.08 to $19.68 \mathrm{ppb}$ in Siwaliks [18]

Most of these samples i.e. $77.5 \%$ (76 samples out of 98) were found to be below the detection limit for post monsoon period. Details results of the frequency distribution of uranium of in Cuttack district of Odisha for post monsoon period are presented in Fig. 3 as follows. It is observed that all the collected samples the uranium concentration for was found to be well below the permissible limit (30 ppb) recommended by United States Environment Protection Agency [3] and World Health Organization [4]. 

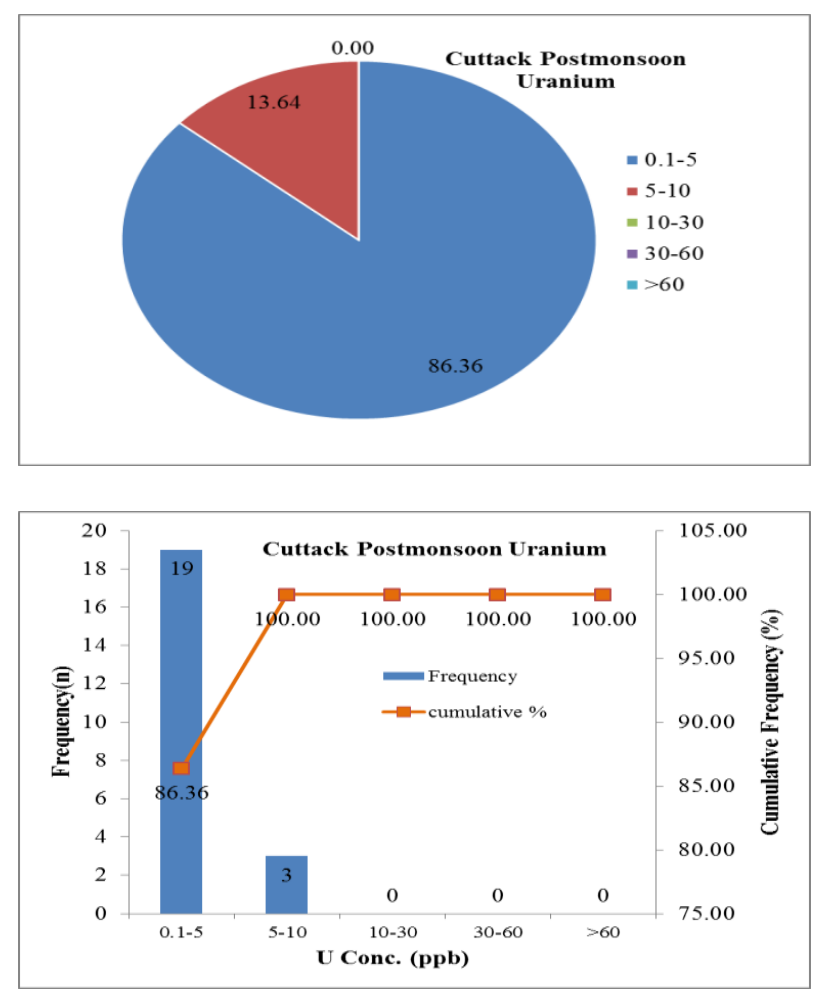

Fig. 3 (a), (b) Frequency distribution of uranium of in Cuttack districts of Odisha of post monsoon samples.

In three (3) of the post monsoon samples the uranium concentration estimated more than $5 \mathrm{ppb}$. This might be the application of phosphate fertilisers in agricultural process in some of the study area particularly Cuttack district. Which is well supported by reported literature that the increase in anthropogenic radio activities due to phosphate fertilisers in ground water [19]. Kawabata et al (2006) [20] reported the concentration of uranium in phosphate fertilizers varies from $1 \mathrm{mg} / \mathrm{kg}$ to $68.5 \mathrm{mg} / \mathrm{kg}$. Therefore, application of phosphate rocks in manufacture of phosphorous fertilizers might have contributed the concentration of uranium in groundwater of agricultural land particularly in Cuttack district.

Details about the spatial distribution of uranium in post monsoon period of Cuttack district is shown in Fig.4.

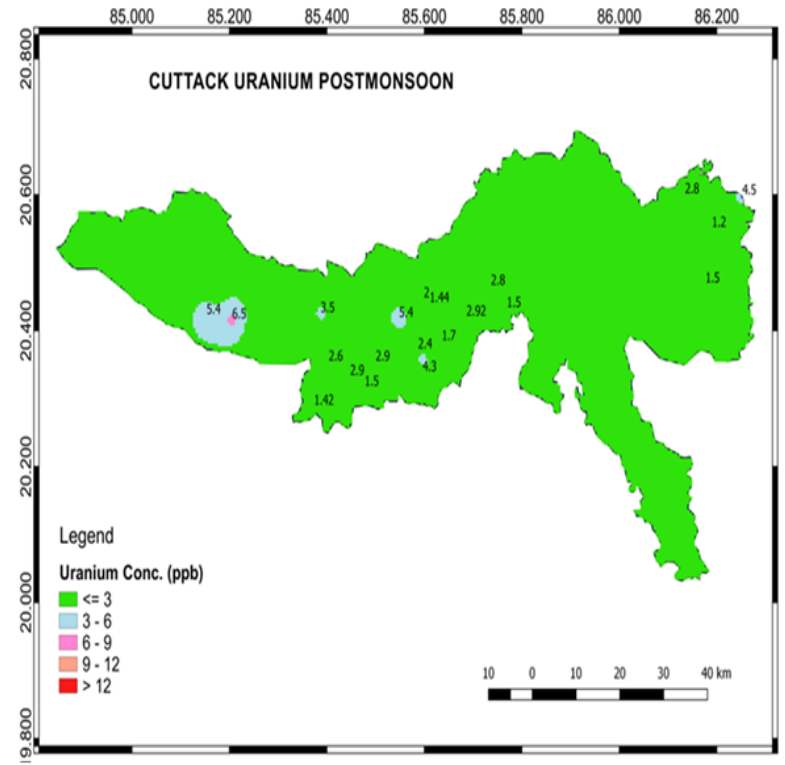

Fig. 4. Spatial distribution of uranium in pre and post monsoon period of Cuttact and Jajpur district.

\section{E. Gamma radiation}

The terrestrial gamma radiation in air in the study area in the range of $60-460 \mathrm{nSv} / \mathrm{h}$ in post monsoon period. Source of these radiations is radioactive nuclei, which is present at that particular location and responsible for $\gamma$ radiation. Some discrepancy also observed in study which need deeper analysis and interpretation further. Details results of the frequency distribution of gamma radiation of in Cuttack for post monsoon period are presented Fig. 5 as follows.

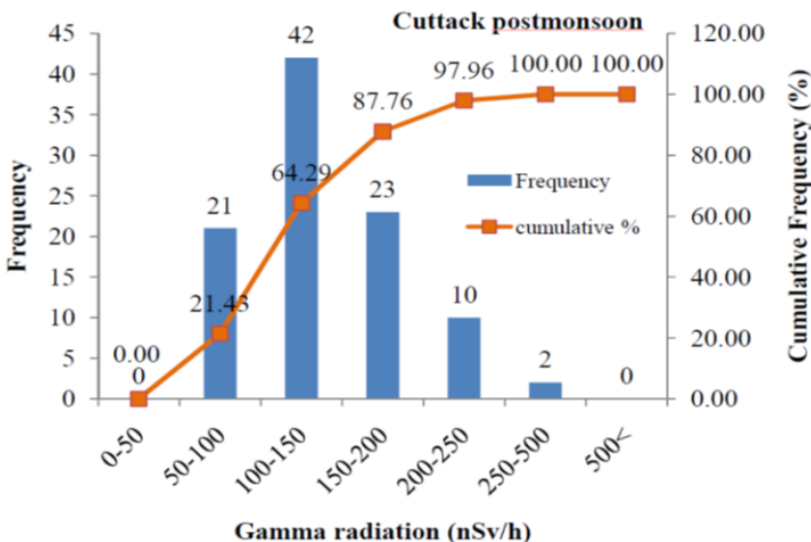

Fig. 5. Frequency distribution of gamma radiation of Cuttack district for post monsoon samples.

\section{F. Nitrate, phosphate and sulphate profile}

Other redox-sensitive water quality parameters are due to presence of the nitrogen compounds, mainly nitrate.The nitrate concentration in the study area is varies from 1.8 $86.25 \mathrm{mgl}-1$ for post monsoon period. The distribution of nitrate is revealed that more than $70.4 \%$ (69 out of 98 samples) of the post monsoon collected water samples were concentration below $45 \mathrm{mgl}-1$ (group A) i.e. below the permissible limit as per WHO (2011) [4]guide line.. The ground water nitrate concentration in the present study is well supported by several literatures such as 0.24-85.01 mgl-1 [7], 3.8-77.8 mgl-1 [21]. There are few samples with an outstanding high nitrate concentration near about $80 \mathrm{mgl}-$ 1. The reason for such extremely high nitrate levels remains unclear. In few samples the presence of higher concentration of nitrate might be application of nitrogen (N)-fertilizer as well as manure of animals in agriculture land which percolated deep into the ground water consequently increases the nitrate concentration of ground water [22],[23]. Similarly, waste organic and inorganic materials, septic tanks are one of the anthropogenic sources of nitrate concentration in ground water.

Further, the presence of different type of rock such as metamorphic, sedimentary bedrock, quartz, granite rock etc in the study area and the soil/rock-water interactions might have enhances the weathering and enhancement of ammonium ions, nitrate concentration in groundwater which is well supported by several authors in literature [24]. It is also reported that the nitrate concentration in basaltic aquifers is found to be below $45 \mathrm{mgl}-1$ (Below permissible limit), whereas, granitic aquifers concentration of nitrate were varied from 22.2 to $178 \mathrm{mgl}-1$ [22]. When the 
concentration of nitrate increases beyond $100 \mathrm{mgl}-1$ in drinking water, it causes methamoglobinemia or blue baby disease in infants. Similarly high TDS in drinking water human. It is observed that some ground water samples particularly alluvial and deltaic aquifers, river bank of the study area the concentration of nitrate found to be very low.

In the present study the range of phosphate concentration is varied from, BDL to $3.2 \mathrm{mgl}-1$ for post monsoon Cuttack. In the present study some of the post monsoon ground water the values of phosphate is found to be very high, this might be due to anthropogenic activities mainly input of fertilizers employed to agricultural land, agriculture run off, and decomposition of organic matter washer man activity.

The range of sulphate concentration is varied from BDL to $194 \mathrm{mgl}-1$ for post monsoon of Cuttack district. Most of the collected ground water samples in the study area found to be below the permissible limit of $200 \mathrm{mgl}-1$ set by WHO (2011) [4]. The median sulphate concentration is estimated to be $22.5 \mathrm{mgl}-1$ for post monsoon samples. Similar sulphate concentration also reported in several literatures such as; 1.85-88.00 mgl-1 [7] 50-132 mgl-1 Angul [11] 53-256 mgl1 1.2-207 mgl-1 in Angul [12].

\section{G. Chloride profile}

Chloride is the dominating anion in saline water. The range of chloride concentration is varied from BDL- 327.5 ppm for post monsoon period of Cuttack district. The chloride concentration in the present study is very well correlated with that of several reported literature for instance; 17.06-150.81 mgl-1 [7] 10.9-387 mgl-1 [21], 40$335 \mathrm{mgl}-1$ [15]. Chloride is the dominating anion in saline water. Most of the water samples in the study area the chloride concentration i.e. 95.91\% (94 samples out of 98) post monsoon is below the maximum ISI permissible limit of drinking water, i.e. $250 \mathrm{mgl}-1$.

The distribution of chloride is therefore more or less identical with the electrical conductivity pattern. In general, freshwater samples contain more sodium $(\mathrm{Cl} / \mathrm{Na}$ ratio $<1)$ on the other hand, saline waters lower sodium but higher chloride. But in the present study the concentration of chloride is comparatively less which clearly indicated that the samples are not saline water. The obtained trend is due to the water-rock interaction in fresh and saline water environments. The two major sources of sodium and chloride in fresh water: a) Sea salt in rain water with a $\mathrm{Cl} / \mathrm{Na}$ ratio of 1.17 and b) The hydrolytic decomposition of silicates, which leads to liberation of supplementary sodium (but not chloride). Freshwater therefore commonly has $\mathrm{Cl} / \mathrm{Na}$ ratios of less than one. In some study area contamination of the high chloride concentration might be due to the extensive application of inorganic fertilizer, leachates of land fill, effluent of septic tank and industrial waste which percolated and contaminated the ground water.

\section{H. Hardness}

In general, hardness in water is principally due to presence of limestone. All the samples analyzed showed the total hardness varying from 20-200 mgl-1 for post monsoon. The maximum permissible limit of total hardness for drinking water is $600 \mathrm{mgl}-1$ as Bureau of Indian Standards causes gastro-intestinal irritation and laxative effects in

[9] and 500 mgl-1 set by [4]. Therefore, in the present study area the concentration of total hardness found to be under acceptable range as per WHO (2011) [4] and BIS (2012) [9] guide line. In the present study the concentration of calcium varied from 20 to $160 \mathrm{mgl}-1$. The ISI permissible limit of calcium is $75 \mathrm{mgl}-1$. In general, $98 \%$ of world wide ground water samples are governed by presence of calcium and bicarbonate ions which may be due to the weathering of lime stone in the catchment area and underground water beds. Generally higher hardness causes calcification in arteries, kidney and stomach disorders. The high concentration of total hardness in some places of the study area might be due to dissolution of polyvalent metallic ions from sedimentary rocks in addition, seepage and run off from soil also increase hardness in the study area which is well correlated with literature report [15]. The high value of hardness is further aggravated by percolation of large quantity of sewage as well as detergent from the nearby residential localities. Similar, hardness profile (43 - 672 mgl-1) also reported by other researchers in Angul and Talcher zone [12]

\section{Alkalinity}

In the present study the minimum and maximum alkalinity concentration varies from 20-680, mgl-1 for Cuttack district. . The spatial distribution of alkalinity in the study area is shown in the Fig. 6.

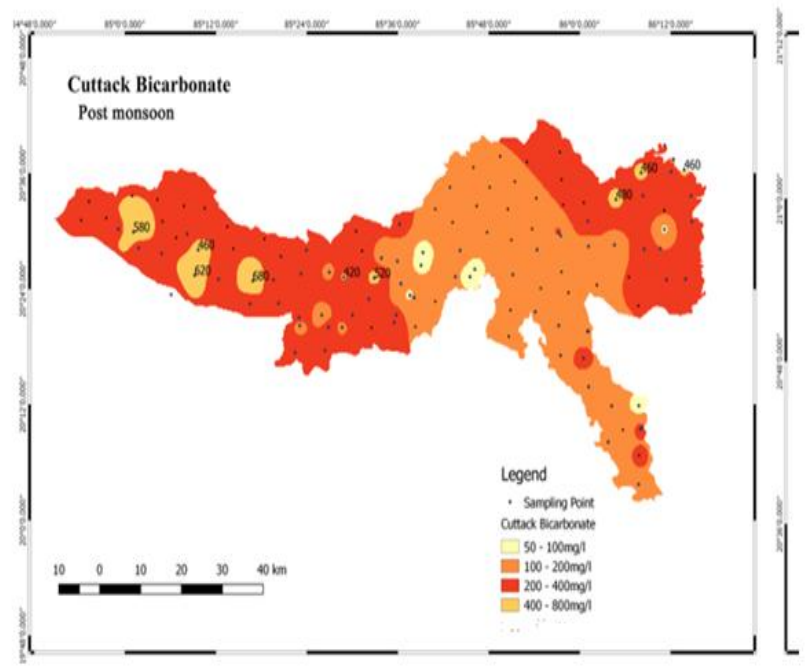

Fig.6. Spatial distribution of bicarbonate in post monsoon period of Cuttack district

In the study area, mostly bicarbonate alkalinity shown to be at elevated concentration might be due tothe weathering and dissolution of mineral sedimentary and metamorphic rock of Cuttack. In addition, low water table might be bringing down the rate of decomposition of salts to a minimum consequently raises in the alkalinity. The ground water alkalinity profile of the present study shows very good match with that of several literature reported value from different region of India such as 212.67-408 mgl-1 [7], 153 to $475 \mathrm{mgl}-1$ [8]. 205 -542 mgl-1 in Angul district [11] 
In general, the $\mathrm{pH}$ of the alluvial groundwater is controlled by the $\mathrm{HCO} 3$ and $\mathrm{H} 2 \mathrm{CO} 3$-buffer system, where $\mathrm{H} 2 \mathrm{CO} 3$ stands for the sum of carbonic acid and $\mathrm{CO} 2$. For the collected samples, the median $\mathrm{pH}$ is 6.5 (min. $\mathrm{pH} 4.6$, max. $\mathrm{pH}$ 7.3) and which clearly indicated the collected samples are not falls under the alkaline range leading to lower concentrations of CO32-. Similar value of $\mathrm{pH}$ also reported by other researchers in literature for instance; 6.60 7.10 [7], 7-7.3 [11] and 7.0 to 8.1 [8].

\section{K. Correlation study}

The electrical conductivity is positively correlated with $\mathrm{pH}$ and the estimated correlation coefficient is 0.299 post monsoon samples which is well supported by many literatures. The estimated correlation factor between TDS and EC is found to be 1 for post-monsoon and found highly significance. The correlation table shows a clear positive relation between sulphate and salinity of 0.675 post monsoon data. The median concentration of fluoride is in the range of 0.37 to $1.16 \mathrm{mgl}-1$ in four district of Odisha (min. BDL mgl-1, max. $3.4 \mathrm{mgl}-1$ ), there is positive correlation between $\mathrm{pH}$ and fluoride value 0.641 as shown in Table 1. Generally higher $\mathrm{pH}$ displaces fluoride ions from the mineral surface. From the correlation analysis it is found that higher concentration of fluoride in water is associated with high $\mathrm{pH}$ values. In the present study, the total hardness is significantly positively correlated with chloride, the correlation coefficient estimated to be 0.462 and 0.408 for post monsoon. Similarly the correlation coefficient between calcium and chloride is very high i.e. 0.500 for post monsoon, which strongly supported the existence of calcium in the study area is predominantly in the form of $\mathrm{CaCl}$. The ISI permissible limit of sulphate is $200 \mathrm{mgl}-1$. Sulphate shows moderately positive correlation with $\mathrm{Ca} 2+$ with correlation coefficient value of 0.395 for post monsoon . Whereas, correlation coefficient value of 0 . 0.193 between sulfate and magnesium $(\mathrm{Mg}+2)$ found to be insignificant, which strongly indicated that presence of calcium sulphate might be the predominant form with compare to magnesium sulphate.

Table 1 Correlation matrix of ground water quality data of Cuttack district

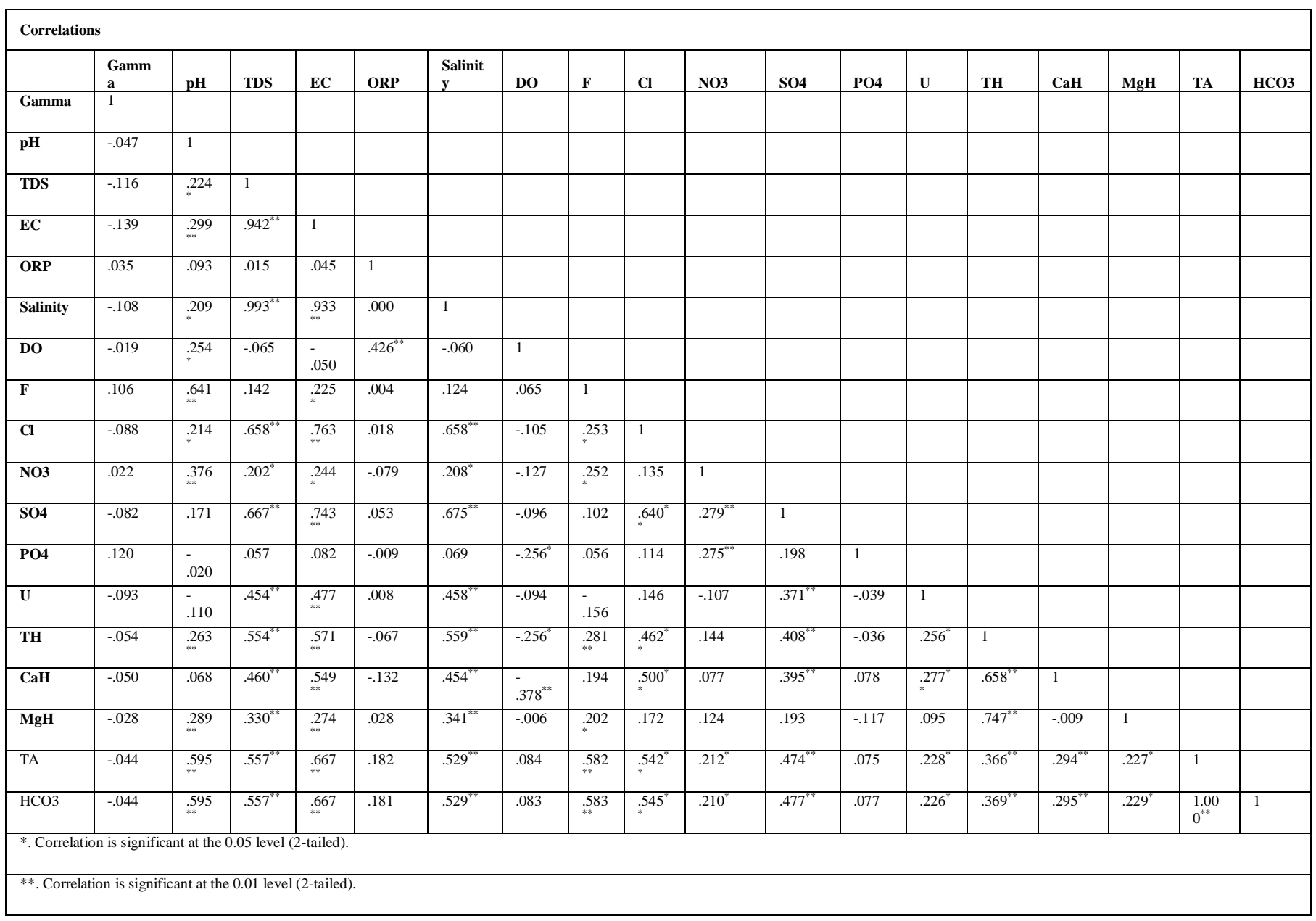

Similarly, nitrate shows quite insignificant, positive correlation with $\mathrm{Ca} 2+$ and magnesium with value of 0.077 and 0.124 which clearly revealed that the that presence of $\mathrm{Ca}(\mathrm{NO} 3) 2$ and $\mathrm{Mg}(\mathrm{NO} 3) 2$ might be very less in the water samples. Table 1 represented the linear correlation matrix of the of the water quality parameter obtained in the study. A little positive correlations between uranium (U) with sulpahte is observed (0.371)., however it remain unresolved in the present study. 


\section{CONCLUSION}

Concentration of bicarbonate, calcium and magnesium are high in study area, it may be due mineral dissolution as well as natural and anthropogenic activities that increase the concentration of these cations and anions by percolation and infiltration. The $\mathrm{pH}$ of the alluvial groundwater is controlled by the HCO3. Some of the samples nitrate and sulphate concentrations are largely elevated than the WHO 2004 permissible limit might be due to fertilizers and organic matter dissolution. Domestic sewage also contributes in nitrate and sulphate contamination. However, 70.4\% (69 out of 98 samples) of the post monsoon collected water samples were concentration nitrate is below $45 \mathrm{mgl}-1$ (group A) i.e. below the permissible limit as per WHO guide line. Apart from few samples, $90.81 \%$ samples comes under the category of quality group A ( $<1 \mathrm{mgl}-1$ fluoride). Similarly, 8 are categorized under group B (between 1-2 mgl-1). However one outlier contains a significantly higher fluoride concentration in the samples code C-11 (Pithakhai, Narassinghapur) is $2.38 \mathrm{mgl}-1$, which is harmful for consumption of human. All the groundwater samples have uranium concentration below the provisional WHO guideline value of $30 \mathrm{ppb}$. The terrestrial gamma radiations in air in the study area are in the range of $10-800 \mathrm{nSv} / \mathrm{h}$ in pre monsoon period where as incase of post monsoon it is 60- $460 \mathrm{nSv} / \mathrm{h}$. Some discrepancy also observed in study which need deeper analysis and interpretation further.

\section{ACKNOWLEDGEMENTS}

The authors acknowledge the financial support received from the National Uranium Project Funded by BRNS, DAE, Government of India, BARC, Mumbai, for carrying out this research work.

\section{REFERENCES}

1. A. I. Selden et al., "Nephrotoxicity of uranium in drinking water from private drilled wells \$," Environ. Res., vol. 109, pp. 486-494, 2009.

2. D. Larivière, S. Y. Tolmachev, V. Kochermin, and S. Johnson, "Uranium bone content as an indicator of chronic environmental exposure from drinking water," J. Environ. Radioact., vol. 121, pp. 98-103, 2013.

3. USEPA "U.S. Environmental Protection Agency office drinking-water quality - 4th edition, World Health Organization, Geneva, 2011.

5. K. Brindha, L. Elango, and R. N. Nair, "Spatial and temporal variation of uranium in a shallow weathered rock aquifer in southern India," J. Earth Syst. Sci., vol. 120, no. 5, pp. 911-920, 2011.

6. APHA Standard Methods for the Examination of Water and Waste Water, 21th edition, American Public Health Association, Washington DC, 2005.

7. N. Kumar, S. Kumar, and D. P. Singh, "Ground water quality evaluation at suburban areas of Lucknow, U . P ., Int. J. Environ. Sci., vol. 6, no. 3, pp. 376-387, 2015.

8. U. Saxena and S. Saxena, "Correlation study on physicochemical parameters and quality assessment of ground water of bassi tehsil of district jaipur, rajasthan, india," Suresh Gyan Vihar Univ. Int. J. Environ. Sci. Technol., vol. 1, no. 1, pp. 78-91, 2015. of water, radionuclide's in drinking water", 2000.

4. WHO (World Health Organisation) Guidelines for

9. BIS,. Bureau of Indian Standards, drinking water specification (second revision) ICS 13.060.20, IS 10500:2012 New Delhi, 2012.

10. V. Pradeep, C. Deepika, G. Urvi, and S. Hitesh, "Water Quality Analysis of an Organically Polluted Lake by Investigating Different Physical and Chemical Parameters International Journal of Research in Chemistry and Environment Water Quality Analysis of an Organically Polluted Lake by Investigating Diffe," Int. J. Res. Chem. Environ., vol. 2, no. May 2014, pp. 105-111, 2012.

11. M. Sahoo, M. R. Mahananda, and P. Seth, "PhysicoChemical Analysis of Surface and Groundwater around Talcher Coal Field ," J. Geosci. Environ. Prot., vol. 4, no. February, pp. 26-37, 2016.

12. T. Keesari, U. K. Sinha, and P. Kamaraj, "Groundwater quality in a semi-arid region of India: Suitability for drinking, agriculture and fluoride exposure risk," J. Earth Syst. Sci., 2019.

13. Nanda, P.M., Garnaik, B.K., Panda, S., 2011. Studies on Fluoride Pollution in ground water of Angul-Talcher industrial complex of Odisha. Asian J. Chem. Environ Res., 4(1):13-16

14. CGWB, 2010. Ground water quality in shallow aquifers of India, Central Ground Water Board, Ministry of Water Resources, Government of India, Faridabad (http://admin.indiaenvironmentportal.org.in/files/GW_Q uality_in_shallow_aquifers.pdf)

15. J. Dutta, M. Nath, M. Chetia, A.K. Misra, "Monitoring of Fluoride Concentration In Ground Water of Small Tea Gardens in Sonitpur District, Assam, India: Correlation with physico-chemical Parameters," International Journal of ChemTech Research, vol. 2, no. 2, pp. 1199-1208, 2010.

16. H. Garshasbi, J. K. Diba, M. H. Jahanbakhshian, S. K. Asghari, and G. H. Heravi, "Measurements of natural uranium concentration in Caspian Sea and Persian Gulf water by laser flourimetric method," Iran. J. Radiat. Res., vol. 3, no. 3, pp. 123-127, 2005.

17. R. C. Ramola, S. Singh, and H. S. Virk, "URANIUM A N D R A D O N E S T I M A T I O N IN SOME WATER SAMPLES F R O M H I M A L A Y A S Llnglot," Nucl. Tracks Radiat. Meas., vol. 15, pp. 791793, 1989.

18. J. Singh, H. Singh, and S. S. B. S. Bajwa, "Estimation of uranium and radon concentration in some drinking water samples of Upper Siwaliks , India," Environ. Monit. Assess., vol. 154, pp. 15-22, 2009.

19. C. Roselli, D. Desideri, and M. A. Meli, "Radiological characterization of phosphate fertilizers: Comparison between alpha and gamma spectrometry," Microchem. J., vol. 91, no. 2, pp. 181-186, 2009.

20. Y. Kawabata, M. Yamamoto, V. Aparin, S. Ko, K Shiraishi, M. Nagai and Y. Katayama, "Uranium pollution of water in the western part of Uzbekistan," J. Radioanal. Nucl. Chem.,vol. 270, no. 1, pp. 137141,2006

21. B. S. Meena and N. Bhargava, "PHYSICO-CHEMICAL CHARACTERISTICS OF GROUNDWATER OF SOME VILLAGES OF DAG BLOCK IN JHALAWAR DISTRICT OF RAJASTHAN STATE ( INDIA )," Rasayan J. Chem., vol. 5, no. 4, pp. 438-444, 2012.

22. H.W. Khandare, "Scenario of Nitrate contamination in Groundwater: Its causes and Prevention," International Journal of ChemTech Research vol. 5, no. 4, pp. 1921$1926,2013$. 
23. S. K. Tank and R. . Chippa, "Analysis of Water Quality of Halena Blocks in Bharatpur. International Journal of Scientific and Research Publications.”pp. 1-6, 2013.

24. A. N. Amadi, "Effects of urbanization on groundwater quality: A case study of Port-Harcourt, Southern Nigeria," Natur. Appl. Sci. J., vol. 11, no. 2, pp. 143-152, 2010.

\section{AUTHORS PROFILE}

First Author Manas Ranjan Naik, completed her Msc in Chemistry from National Sambalpur University, Jyoti Vihar, Burla, India. Currently, he is doing PhD in the Department of Chemistry Environmental Science and Technology Programme, Institute of Technical Education and Research, Siksha 'O'Anusandhan, Deemed to be University, India, Her area of research area is spatial distribution of uranium and associated ground water quality and its remediation.

Second Author Manas Barik, completed her Msc Environmental Science from Sambalpur University, Jyoti Vihar, Burla, India. Currently, he is doing $\mathrm{PhD}$ in the Department of Chemistry Environmental Science and Technology Programme, Institute of Technical Education and Research, Siksha'O'Anusandhan, Deemed to be University, India, His area of research is treatment of coke oven wastewater using multistage bioreactor system.

Fifth Author N.K. Sahoo is working as an Associate Professor in the Department of Department of Chemistry Environmental Science and Technology Programme, Institute of Technical Education and Research, Siksha'O'Anusandhan, Deemed to be University, India, After M-Tech in Biotechnology from Jadavapur University, Kolkata India, he has received his $\mathrm{PhD}$ from Centre for the Environment from Indian Institute of Technology Guwahati, India. His research interests are in the area of industrial wastewater treatment using photo catalytic nano-composites, nano-adsorbent and bioremediation techniques. He has published over 20 papers in peer reviewed international journals book and book chapter. He is a invited reviewer of many scientific journals including, CLEAN - Soil, Air, Water, Wiley publisher, International Journal of Hydrogen Energy, Elsevier Publisher, Industrial and Engineering and Chemistry Research, ACS, Publisher, Biodegradation, Springer publisher, Chemical Technology and Biotechnology, Wiley publisher, Review in Environmental Science and Biotechnology, Springer publisher, Environmental Process Springer publisher. He is life member of biotechnology society of India 